\title{
Functional relevance of the precuneus in verbal politeness.
}

\section{$\operatorname{AUTHOR}(\mathrm{S})$ :}

Ashizuka, Aoi; Mima, Tatsuya; Sawamoto, Nobukatsu; Aso, Toshihiko; Oishi, Naoya; Sugihara, Genichi; Kawada, Ryosaku; Takahashi, Hidehiko; Murai, Toshiya; Fukuyama, Hidenao

\section{CITATION:}

Ashizuka, Aoi ...[et al]. Functional relevance of the precuneus in verbal politeness.. Neuroscience research 2015, 91: 48-56

\section{ISSUE DATE:}

2015-02

URL:

http://hdl.handle.net/2433/197290

\section{RIGHT:}

(c) 2014 Elsevier Ireland Ltd and the Japan Neuroscience Society. NOTICE: this is the author's version of a work that was accepted for publication in Neuroscience research. Changes resulting from the publishing process, such as peer review, editing, corrections, structural formatting, and other quality control mechanisms may not be reflected in this document. Changes may have been made to this work since it was submitted for publication. A definitive version was subsequently published in Neuroscience research, 91 48-56 (2015), doi:10.1016/j.neures.2014.10.009; This is not the published version. Please cite only the published version.; この論文は出版社版でありません。引用の際には出版社版 をご確認ご利用ください。 
Title: Functional relevance of the precuneus in verbal politeness

\author{
Authors: \\ Aoi Ashizuka ${ }^{1}$, Tatsuya Mima ${ }^{1 *}$, Nobukatsu Sawamoto ${ }^{1}$, Toshihiko Aso ${ }^{1}$, Naoya Oishi ${ }^{1}$, Genichi Sugihara ${ }^{2}$, \\ Ryosaku Kawada², Hidehiko Takahashi², Toshiya Murai², Hidenao Fukuyama ${ }^{1}$. \\ Correspondence to: \\ Tatsuya Mima, M.D., Ph.D. \\ Human Brain Research Center, Kyoto University Graduate School of Medicine, 54 Shogoin Kawahara, Sakyo, \\ Kyoto 606-8507, Japan. \\ mima@kuhp.kyoto-u.ac.jp

\section{Affiliations:} \\ ${ }^{1}$ Human Brain Research Center, Kyoto University Graduate School of Medicine, 54 Shogoin Kawahara, Sakyo, \\ Kyoto 606-8507, Japan. \\ ${ }^{2}$ Department of Psychiatry, Graduate School of Medicine, Kyoto University, 54 Shogoin Kawahara, Sakyo, \\ Kyoto 606-8507, Japan.
}

\title{
Acknowledgments:
}

This study was partly supported by Grants-in-Aid for Scientific Research (B) (24300192) and for Exploratory Research (24650226) (to T.M.) from the Japan Society for the Promotion of Science.

The authors declare no competing financial interests. 


\begin{abstract}
:
Non-competitive and non-threatening aspects of social hierarchy, such as politeness, are universal among human cultures, and might have evolved from ritualized submission in primates; however, these behaviors have rarely been studied. Honorific language is a type of polite linguistic communication that plays an important role in human social interactions ranging from everyday conversation to international diplomacy. Here, functional magnetic resonance imaging (fMRI) revealed selective precuneus activation during a verbal politeness judgment task, but not other linguistic-judgment or social-status recognition tasks. The magnitude of the activation was correlated with the task performance. Functional suppression of the activation using cathodal transcranial direct-current stimulation reduced performance in the politeness task. These results suggest that the precuneus is an essential hub of the verbal politeness judgment.
\end{abstract}

\title{
Keywords:
}

Politeness, Precuneus, fMRI, tDCS, 


\section{Introduction}

Hierarchy is universal in social species, and organizes inter-individual interactions and communication. Social cognition of dominance and ranking has been observed in species of primates(Bergman et al., 2003), birds(Paz-y-Mino et al., 2004), fish(Grosenick et al., 2007), and ants(Blacher et al., 2010; Xu and Chen, 2010). In primates, the relevance of social hierarchy is not confined to agonistic and sexual competition. Ritualized submission cues from losers can elicit social reconciliation in potentially aggressive encounters, reinforcing the social hierarchy(de Waal, 1986). This kind of social behaviors observed in animals might be similar to human “politeness” (Brown and Levinson, 1987). However, the influence of human "politeness” is complex and sophisticated in comparison with social behaviors of animals and ranges from everyday social etiquette to formal diplomatic protocols. Politeness can be defined as a behavior that is respectful and considerate of other people. Politeness is thus not merely the social cognition of dominance, but rather social behavior that often relates to hierarchy. This context-dependent behavior modification might require self-referential cognition of social hierarchy. Politeness can be expressed in both verbal and non-verbal way. For example, the respect to the other person can be represented in special dress codes, facial expressions, gestures or bodily postures.

Regarding the verbal politeness, its formal manifestation is honorific language (verbally-expressed politeness directed towards higher-status individuals) (Fukada and Asato, 2004; Shibatani, 1990; Yoshimura and Macwhinney, 2011). Humans commonly use polite language when addressing socially superior individuals; however, some languages, including Japanese, Korean, and Tibetan, include a complex system of honorifics, which represent "grammaticalized" outputs of politeness(Brown and Levinson, 1987). In contrast to animals’ submissive behavior, human verbal politeness is very sofisticated and related to multiple dimensions of social hierarchy, such as social intimacy/distance, age, profession and family/kinship.

Neuropsychological studies have reported impairments of social-hierarchy judgment associated with prefrontal cortex damage(Karafin et al., 2004; Mah et al., 2004). Neuroimaging have also investigated the brain processing of social hierarchy(Cheon et al., 2011; Chiao et al., 2009b; Freeman et al., 2009; Marsh et al., 2009; Muscatell et al., 2012; Zink et al., 2008). However, little is known about the neural representation of verbal politeness. A functional magnetic resonance imaging (fMRI) study showed involvement of Broca’s area in grammatical aspects of honorific expression(Momo et al., 2008). Moreover, a Japanese case report 
described a patient with semantic dementia who used honorifics in all situations(Kokuryu and Takechi, 2011). However, to our knowledge, the brain representation of politeness has not previously been investigated.

We investigated the neural correlates of verbal aspect of politeness using fMRI and transcranial directcurrent stimulation (tDCS) by applying the honorific judgment task. Japanese honorification employs different verb forms for socially superior individuals(Shibatani, 1990). We hypothesized that an honorific-judgment task would activate brain areas associated with verbal politeness, in addition to language- or status recognitionrelated networks. Cathodal or suppressive tDCS with the same task confirmed the relationship between politeness and brain activation suggested by the fMRI analysis.

\section{Materials and Methods}

\section{Subjects}

Thirty-two right-handed healthy native Japanese university students participated in the experiments (mean age \pm standard deviation [SD], $24.4 \pm 5.0$ years; five females and 27 males). To control the social ranking of the subjects, we recruited only university students for this experiment. None of the subjects had a history of any neurological or psychiatric disorders according to self-report. All were right-handed as assessed by the Edinburgh scale(Oldfield, 1971). All participants gave written informed consent. The study protocol was approved by the Kyoto University Graduate School and Faculty of Medicine Ethics Committee.

\section{Sentence stimuli}

The main visual stimuli consisted of 20 paired sentences (40 sentences) comprising normal and honorific expressions: each pair described the same action using equivalent-status and high-status subjects respectively (for example, a friend vs. a teacher). The politeness-judgment task employed additional 40 error sentences in which there was a mismatch between the subject and verb according to the honorific-expression system (that is, a high-status subject with a normal verb and an equivalent-status subject with an honorific verb). For the syntax- and semantic-judgment tasks, grammatically incorrect sentences with errors in the use of particles and semantically inappropriate sentences with errors in the use of verbs were prepared (40 each). The control 
condition with minimal linguistic requirements utilized stimuli with a white square in the middle of a sentence (Table 1).

Each sentence stimulus was between 10 and 13 letters in length (visual angle, $8.8^{\circ}$ in height and $26.0^{\circ}$ in width). The familiarity rating did not differ significantly between simple $(5.75 \pm 1.11)$ and suppletive (5.22 \pm 0.86 ) verbs, and was above average according to the word-familiarity rating of the Nippon Telegraph and Telephone (NTT) database score (4.17 \pm 1.32$)$. Table 1 shows examples of sentences used in the judgment tasks for Experiments 1 and 2. Errors are underlined. Japanese honorific expressions involve two kinds of verb: the regular form, which is transformed from the corresponding simple verb through a morphological process; and the suppletive form, in which the simple verb is replaced by a lexically different verb when the subject is superior to the speaker(Iyer et al., 2005). We used the suppletive form in this task. In modern Japanese language, the use of honorific expression becomes less in frequency during everyday life, especially in young people. However, we asked the subject to follow the strict traditional rules of honorific expression as taught in the elementary school. It is the limitation of the study that this instruction might affect the results.

\section{Experimental task}

Each experimental session consisted of 20 task blocks separated by a rest period and the presentation of a fixation point (for 9 s). Four types of task block were employed: "Politeness (Po)”, "Semantic (Sem)”, "Syntax (Syn)”, and "Control (Co)” (Fig. 1). The task-block order was aligned pseudo-randomly. Each task block (15 s) was preceded by an instruction cue ("Honorific”, "Syntax”, "Semantic”, or "Square”) of 3 s, and followed by a rest period of $3 \mathrm{~s}$. Each task block included four trials (two errors), in which the stimulus sentence was presented for $3.4 \mathrm{~s}$, followed by presentation of a fixation point (for $0.35 \mathrm{~s}$ ). In spite of the short rest period duration (9 s), the stimulus-onset asynchrony of the task block (15 s) was $30 \mathrm{~s}$, which was in accord with the hemodynamic response function. Moreover, we pseudo-randomized the task-block in order to minimize the overlap of task-related brain responses.

Subjects were asked to indicate whether the presented sentence was correct by pressing non-magnetic buttons using their right index or middle finger. For the control task, subjects were asked to indicate whether they observed a square in the middle of the sentence by pressing buttons. Each task block appeared five times 
during a session. Stimuli were presented and behavioral data were collected using E-prime software (Psychology Software Tools, Inc., Pittsburgh, PA).

For an additional experiment in fMRI to distinguish between politeness and cognition of status in these subjects, we used the same set of stimuli as the politeness-judgment task using an instruction cue of "Status" and asked the subjects to indicate whether the subject of a sentence appeared socially superior by pressing a button. This experiment involved both the Status and Control (“Square”) tasks. Each task block appeared 10 times during a session.

Each sentence stimulus was between 10 and 13 letters in length (visual angle, $8.8^{\circ}$ in height and $26.0^{\circ}$ in width). The familiarity rating did not differ significantly between simple (5.75 \pm 1.11$)$ and suppletive (5.22 \pm 0.86 ) verbs, and was above average according to the word-familiarity rating of the Nippon Telegraph and Telephone (NTT) database score (4.17 \pm 1.32$)$. Table 1 shows examples of sentences used in the judgment tasks for Experiments 1 and 2. Errors are underlined. Japanese honorific expressions involve two kinds of verb: the regular form, which is transformed from the corresponding simple verb through a morphological process; and the suppletive form, in which the simple verb is replaced by a lexically different verb when the subject is superior to the speaker(Iyer et al., 2005). We used the suppletive form in this task.

\section{Experiment 1 (fMRI)}

For fMRI, 20 right-handed healthy native Japanese university students were monitored using a 3-Tesla wholebody scanner equipped with an eight-channel phased-array head coil (Trio, Siemens, Erlangen, Germany) while performing a sentence-judgment task using a block design involving two sessions of 600-s duration. Subjects lay in a supine position on a scanner bed, wearing earplugs. They held a button-response device with their right hand. During the sessions, subjects viewed visual stimuli projected onto a screen through a mirror.

\section{MRI data acquisition and analysis}

Functional images were acquired with T2*-weighted gradient echo echo-planar imaging (EPI) using the following parameters: slice thickness, 3 mm; 48 axial slices; repetition time (TR), 3 s; echo time (TE), 30 ms; flip angle (FA), $90^{\circ}$; matrix size, $64 \times 64$; and field of view (FOV), $192 \times 192$. A series of EP images were 
obtained parallel to the anterior-posterior commissural (AC-PC) line. The initial two image volumes were discarded at the beginning of each session to allow the MR signal to reach equilibrium.

Preprocessing and image analyses were performed using statistical parametric mapping (SPM) software (SPM8: Wellcome Department of Cognitive Neurology, UCL, London, UK) in MATLAB (version 7; MathWorks, Inc., Natick, MA). Images were corrected for slice-acquisition timing and realigned to the first image to adjust for head movements. The realigned images were then spatially normalized to the template brain defined by the Montreal Neurological Institute (MNI), using a 12-parameter affine registration and nonlinear transformations. The functional images were then resampled to $2 \times 2 \times 2 \mathrm{~mm}$ voxel size and spatially smoothed with a Gaussian kernel of $8 \mathrm{~mm}$ full-width at half-maximum. The data were high-pass filtered with a 128 s cutoff. The hemodynamic response to each block was modeled by a canonical hemodynamic-response function.

Initially, we performed group-level SPM analysis reflecting the simple contrasts for three sentence judgment tasks against the Control (Po vs. Co, Sem vs. Co and Syn vs. Co) and for Politeness task against two other tasks (Po vs. Sem and Po vs. Syn). In addition, common activations across them were investigated by the conjunction analytic procedures based on a conjunction global null hypothesis (Friston et al., 2005; Nichols et al., 2005). Since we used cognitive conjunctions, all the contrasts in the conjunction analysis are not necessarily individually significant. Conjunctively activated voxels were consistently high and jointly significant among contrasts.

We hypothesized the activated regions during Politeness task will be in the areas associated with language processing and social cognition, based on previous neuroimaging studies. For the neural basis of social status hierarchy or status-related mentalizing process, a distinct brain network including the medial prefrontal cortex, dorso- and ventro-lateral prefrontal cortex (DLPFC and VLPFC), precuneus, temporoparietal junction, and posterior inferior parietal lobe (posterior superior temporal sulcus) has been implicated (Chiao et al., 2009a; Chiao et al., 2009b; Frith and Frith, 2006; Iacoboni et al., 2004; Mitchell et al., 2006; Muscatell et al., 2012; Zink et al., 2008). For the brain regions associated with the semantic and syntax processing of written sentences, a largely overlapping left-side dominant network has been reported (Binder et al., 2009; Cappa, 2008; Grodzinsky and Friederici, 2006; Hickok and Poeppel, 2004; Price, 2012; Sakai et al., 2005), 
including the left posterior inferior parietal lobe (IPL), lateral and ventral temporal cortex, dorso- and ventromedial prefrontal cortex, inferior frontal gyrus (IFG) and posterior cingulate cortex, with a special emphasis on the left IFG for the syntactic processing. Thus, based on these hypotheses, we performed the cluster level correction using Monte Carlo simulations with the AlphaSim program (http://afni.nimh.nih.gov) using a mask determined by AAL atlas (Tzourio-Mazoyer et al., 2002). Statistical inferences were performed at the corrected threshold of $\mathrm{p}<0.05$ based on a priori hypothesis and gray matter mask with the voxel-based threshold of uncorrected $\mathrm{p}<0.001$ and a minimum cluster size of 9 voxels.

\section{Experiment 2 (tDCS)}

Based on the fMRI results suggesting the functional relevance of the precuneus in politeness, we conducted the tDCS experiment in an additional 12 subjects. We hypothesized that functional suppression of the precuneus by cathodal tDCS would affect performance of the politeness task if this brain region was essential in politeness.

All subjects took part in two randomized experiments (cathodal and sham tDCS) on separate days. Subjects performed the same Politeness, Semantic, and Syntax sentence-judgment tasks used in the fMRI experiment. After training sessions without tDCS, two sessions, each $150 \mathrm{~s}$, were performed during cathodal or sham tDCS. Each session consisted of 60 sentences presented for $1.0 \mathrm{~s}$, followed by the presentation of a fixation point for $1.5 \mathrm{~s}$. The duration of sentence presentation was shorter than that during fMRI task to avoid the ceiling effects in the accuracy rate.

Two saline-soaked surface-sponge electrodes $\left(5 \times 5 \mathrm{~cm} ; 25 \mathrm{~cm}^{2}\right)$ were positioned over the precuneus (cathodal) and immediately above the right orbit (anodal). Following the previous studies, the cathodal electrode location was determined at Pz of the 10-20 international system for electroencephalogram electrode placement (Homan et al., 1987; Lou et al., 2004; Lou et al., 2010; Luber et al., 2007; Oshio et al., 2010). An electric current (2 mA, $15 \mathrm{~min}$ ) was delivered by a battery-driven direct current (DC) stimulator (CX-6650; Rolf Schneider Electronics, Germany). The experimental task was 6-8 min in duration, and started 5 min after the onset of tDCS. tDCS was applied using the ramp method, in which the initial and final 10-s of electric current gradually increases or decreases. 
In the sham condition, the electric current intensity and voltage were the same as those in the cathodal condition; however, the electric current was applied only for the initial $30 \mathrm{~s}$, so the subjects experienced a similar sensation to that in the cathodal condition. Most subjects report an initial itching sensation during tDCS(Gandiga et al., 2006; Nitsche et al., 2003a; Nitsche and Paulus, 2000). This procedure was intended to prevent awareness of the two different conditions. The stimulation parameters were in accordance with the safety guidelines(Nitsche et al., 2003a; Oshio et al., 2010; Poreisz et al., 2007).

\section{Statistical analysis of behavioral data}

For Experiments 1 and 2, the accuracy rates and reaction times (RT) were used as dependent variables. The normal distribution was tested using the Kolmogorov-Smirnov test. For the accuracy rate, we used Friedman and pair-wise Wilcoxon signed rank tests. For RT, a repeated-measures analysis of variance (ANOVA) was used. The Greenhouse-Geisser correction was used to adjust for sphericity, if appropriate, by changing the degrees of freedom using the correction coefficient epsilon. The post-hoc t-test with the Bonferroni-type correction was used. The threshold of significance was set at $\mathrm{p}<0.05$. All values are presented as the mean \pm standard error of mean (SEM) unless otherwise stated. 


\section{Results}

\section{Experiment 1 (fMRI)}

The mean accuracy rates were $0.95 \pm 0.05,0.98 \pm 0.03,0.98 \pm 0.04$ and $0.99 \pm 0.01$ for Politeness, Semantic, Syntax and Control conditions. For the mean accuracy rate, there was no significant difference using Friedman test. The mean RTs were 1,659 $\pm 298.2,1,745 \pm 322.2,1,692 \pm 307.7$ and 1,459 \pm 323.9 ms for Politeness, Semantic, Syntax and Control conditions. A repeated measures ANOVA demonstrated the significant effect of Condition on RT $[\mathrm{F}(3,60)=15.191, \mathrm{p}<0.001]$. Post-hoc t-test showed the significance between Control and 3 other task conditions $(\mathrm{p}=0.013$ for Politeness vs. Control, $\mathrm{p}=0.001$ for Semantic vs. Control, $\mathrm{p}<0.001$ for Syntax vs. Control). However, the differences among 3 task conditions were not significant.

For the sentence-judgment tasks vs. Control task, similar pattern of brain regions showed significant activation including the left IFG, IPS, and lateral and ventral temporal cortex (Fig. 2A, Table 2). In addition, for the contrast "Po vs. Co", the medial part of precuneus was activated. To clarify the brain areas associated with politeness, we compared the Politeness condition to the two other language tasks: the "Po vs. Sem" contrast showed greater activation than the "Po vs. Syn" contrast, although both exhibited activation of the precuneus and bilateral IPL (Fig. 2B, Table 3). This activation pattern was confirmed by conjunction analysis of the three contrasts; "Po vs. Co", "Po vs. Sem” and "Po vs. Syn”, showing the activation of the precuneus (Fig. 3, Table 3). There was no significant activation for the "Sem vs. Po" and "Syn vs. Po" contrasts. Correlation coefficients revealed a significant negative relationship between the accuracy rate and the \% signal change of the precuneus for the "Po vs. Co" contrast (R $=-0.51, p=0.02$; Fig. 4), but not for the "Po vs. Sem" nor "Po vs. Syn” contrasts.

In addition, group-level SPM analysis revealed no significant activation for the "Status vs. Control” or “Control vs. Status” contrasts with whole-brain analysis.

\section{Experiment 2 (tDCS)}

The mean accuracy rate significantly differed among the six conditions (three tasks each for real and sham tDCS $)$ according to the Friedman test $(p<0.001)$. Pair-wise Wilcoxon signed rank tests showed a significant difference between the real and sham tDCS conditions only for the Politeness task ( $p=0.005$; Fig. 5). The 
mean accuracy rates (real \pm SEM/sham \pm SEM) were $0.80 \pm 0.03$ / 0.87 $\pm 0.02,0.93 \pm 0.02$ / 0.94 $\pm 0.02,0.92 \pm 0.02$ / 0.90 \pm 0.02 , for Politeness, Semantic and Syntax conditions, respectively.

Repeated-measures ANOVA showed no significant difference in RT among the six conditions. The

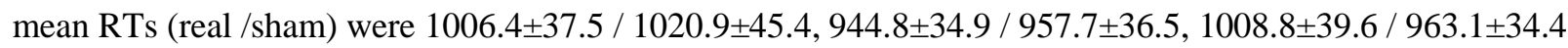
ms for Politeness, Semantic and Syntax conditions, respectively. 


\section{Discussion}

Firstly, the present fMRI study revealed the precuneus activation associated with an honorific linguisticexpression task. The strength of precuneus activation during the politeness-judgment task was correlated with task performance. The precuneus was not significantly activated by the mere social-status judgment task. Secondarily, suppressive interference of the precuneus by cathodal tDCS worsened performance of the honorific judgment task but not other linguistic tasks. These findings indicate that the precuneus is essential for verbal politeness. However, we only studied the verbal politeness using the honorific judgment task, the functional relevance of precuneus in the non-verbal politeness is beyond our scope.

The Politeness, Syntax, and Semantic tasks all activated a similar linguistic brain network, including the left IFG, compared with the control task(Just et al., 1996; Price, 2012; Tatsuno and Sakai, 2005). This was thought to be because all three tasks included visual sentence comprehension. As suggested previously, honorification processing might be related to a grammar function of the left IFG(Momo et al., 2008; Sakai, 2005; Sakai et al., 2002; Suzuki and Sakai, 2003).

There were no significant differences in behavioral parameters among the three task conditions; the politeness-related activation could thus not be attributed to differences in task difficulty. The additional activation of the precuneus during honorific judgment might be related to brain processing of verbal politeness. This activation was unlikely to be simply due to hierarchy cognition, because those areas were not activated during the social status-judgment task.

A significant negative correlation was found between the BOLD signal increase and the performance of the politeness task only for the precuneus activation. Most previous fMRI studies investigating the relationship between brain activation and behavioral score in cognitive tasks involving memory(Bunge et al., 2001; Raichle and Snyder, 2007), go/no-go testing(Holmes et al., 2005), and language(Just et al., 1996; Sakai, 2005; Tatsuno and Sakai, 2005) have shown reduced activation of task-relevant brain regions in subjects with better behavioral outcomes, in line with our findings for politeness and the precuneus. It is likely that poor performers might require more efforts in their brain to accomplish the task. Since we did not find significant correlation between the performance of the politeness task and the BOLD signal increase in the precuneus during "Po vs. Sem" or "Po vs. Syn" contrasts, the exact functional role of precuneus in the verbal politeness 
task is not fully clarified yet. It is plausible that the verbal politeness-related activation during "Po vs. Sem" or "Po vs. Syn" contrasts might have been smaller compared to that during "Po vs. Co" due to the possible implicit minimal activation of politeness-related processing during semantic or syntax tasks compared to control non-linguistic task.

Weak tDCS of the scalp can induce temporary changes in cortical excitability and influence brain activity, such as cognitive and motor functions, in normal human subjects(Bastani and Jaberzadeh, 2012; Priori, 2003). Anodal tDCS has facilitation effects whereas cathodal tDCS causes suppression(Addis et al., 2004; Bastani and Jaberzadeh, 2012; Cabeza et al., 2008; Gilboa et al., 2004; Nitsche et al., 2003b). Here, cathodal tDCS of the precuneus reduced performance only in the Politeness task.

Although the disadvantage of tDCS is its low spatial resolution, regarding its effects in the direction of depth, previous modeling studies suggested that tDCS might be better than repetitive transcranial magnetic stimulation (Miranda et al., 2006; Wagner et al., 2007). However, we cannot exclude the possibility that tDCS in the present study affected not only the medial precuneus but also wider brain areas including the lateral parietal and occipital cortices. In fact, the left SPL might be associated with the brain processing of verbal politeness, since that area was activated for "Po vs. Co" contrast. However, the left SPL was activated also for "Sem vs. Co" and "Syn vs. Co" contrasts and was not activated in the conjunction analysis. Thus, it is likely that the decreased accuracy for politeness task induced by tDCS might not be directly associated with the suppression of the lateral parietal cortices. However, it is still possible that the broad regions including the lateral cortex and the dorsal medial region of precuneus would be stimulated by tDCS, which may influence the responses to the behavioral tasks. Due to the small activation size associated with verbal politeness in the present study, the interpretation of the tDCS results should be cautious because of its low spatial resolution. Since animal model is impossible in investigating the verbal politeness, further careful studies in patients with a localized lesion would be necessary to confirm the functional relevance of precuneus in the verbal politeness.

The functional role of precuneus is unclear but recent neuroimaging studies indicated its relevance in visuo-spatial imagery(Gerardin et al., 2000; Hanakawa et al., 2003; Vogeley et al., 2004; Wan et al., 2011), episodic memory retrieval(Addis et al., 2004; Cabeza et al., 2008; Gilboa et al., 2004; Wagner et al., 2005), 
and self-reference processing or self-awareness(Iacoboni et al., 2004; Kircher et al., 2000; Kjaer et al., 2002; Lou et al., 2004).

Politeness can be considered as self-referential processing, because it involves the recognition of status. Previous works on self-reference processing, the precuneus was recruited by both nonverbal (Ruby and Decety, 2001; Vogeley et al., 2004)and verbal(Kircher, 2003; Northoff et al., 2006) cues. It is tightly interconnected with the medial prefrontal cortices, forming a network associated with representations of the self and external world(Gusnard and Raichle, 2001). It is also implicated in moral thinking(Greene and Haidt, 2002), suggesting politeness could be a type of moral sentiment associated with social hierarchy.

Recent studies suggested functional subdivision within the precuneus(Cavanna and Trimble, 2006; Scheperjans et al., 2008a; Scheperjans et al., 2008b). The anterior precuneus was implicated in self-referential processing, while a posterior region might be associated with episodic memory and visuo-spatial imagery(Cavanna and Trimble, 2006). A comparative study of macaque monkeys and humans identified three functionally-segregated subdivisions of the precuneus using fMRI resting-state connectivity analysis: sensorimotor anterior, cognitive/associative central, and visual posterior parts(Margulies et al., 2009). The peak voxel of activation in the present study was located in an area of the central precuneus involved in cognitive functions, including monitoring information in working memory and action planning, with strong connections to the posterior inferior parietal cortex, adjacent caudal superior temporal sulcus, and DLPFC (Margulies et al., 2009). Similar activation has been reported during self-consciousness or subjective perspective taking(Northoff et al., 2006). Moreover, the activation of pecuneus and dorsomedial prefrontal cortex was observed while the subjects were watching the segment of two persons interaction compared to a single individual activities by video clips, suggesting the importance of precuneus in social cognition (Iacoboni et al., 2004). This supports our hypothesis that politeness is a kind of self-referential cognition that conforms to social hierarchy.

Differences in the activation patterns between the politeness and status tasks indicated that verbal politeness is an active process associated with social-status recognition. We did not detect clear activation caused by judgments of social status, possibly because the task was too simple. However, applying a more liberal threshold to the SPM analysis indicated such activation in the left DLPFC $(p<0.005)$. This was 
consistent with previous fMRI(Zink et al., 2008) and patients(Mah et al., 2004) studies suggesting functional relevance of the DLPFC in hierarchical recognition in a social context. Moreover, since the precuneus was activated by the verbal politeness task but not by the status task, it is likely that the precuneus was specifically related to the behavioral selection in accord with the recognition of social hierarchy. To behave appropriately in the social hierarchy, the subject has to situate himself in the social ranking. Since we did not observe significant precuneus activation during the social-status task, it is possible that the self-referential recognition of social hierarchy without relevant social behavioral modification might not be sufficient to activate the precuneus. This possibility is in agreement with the fact that the precuneus was not activated by simple social hierarchy recognition tasks (Chiao et al., 2009a; Chiao et al., 2009b; Freeman et al., 2009; Marsh et al., 2009; Zink et al., 2008) . However, further studies in precuneus function are necessary to clarify this point.

It is possible that the verbal politeness judgment might be in fact a pragmatic decision but not the expression of sincere respect to other people. Human social behavior including politeness is a kind of theatrical performances in the social interaction, which attempts to control the impression of the self that other persons as audience will develop (Goffman, 1959). In this regard, the distinction between politeness and pragmatic attitude would be difficult. Further studies including the pragmatic judgment task outside of the social hierarchy context would be needed to clarify this point.

Most of previous fMRI studies in social hierarchy focused on the recognition of social superiority (Chiao et al., 2009a; Chiao et al., 2009b; Freeman et al., 2009; Marsh et al., 2009; Muscatell et al., 2012; Zink et al., 2008), which was also true for the status task in the present study. For the politeness task, there were two types of errors; one is the usual verb for the superior subject and the other is the polite verb for the same-status subject. It is likely that the brain activation of the former might be larger, because the former is regarded as ruder impoliteness. However, since we used the fMRI block design, we cannot separate the brain responses for these two types of errors. Further studies are necessary to clarify this point.

Previous studies suggested that the precuneus is strongly interconnected with the IPS, superior temporal sulcus, and DLPFC(Cavanna and Trimble, 2006; Margulies et al., 2009; Zhang and Li, 2012). The precuneus, DLPFC, and IPS might constitute a functional network associated with politeness. This is supported by a previous study indicating the role of the IPS in hierarchy cognition(Chiao et al., 2009a). 
Our current findings suggest that human verbal politeness expressed in the human honorific language might involve both the recognition of social hierarchy in the DLPFC or IPS and the judgment of politeness in conformity with self-referential cognition of social hierarchy in the precuneus. 


\section{References}

Addis, D.R., McIntosh, A.R., Moscovitch, M., Crawley, A.P., McAndrews, M.P., 2004. Characterizing spatial and temporal features of autobiographical memory retrieval networks: a partial least squares approach. Neuroimage 23, 1460-1471.

Bastani, A., Jaberzadeh, S., 2012. Does anodal transcranial direct current stimulation enhance excitability of the motor cortex and motor function in healthy individuals and subjects with stroke: A systematic review and metaanalysis. Clinical Neurophysiology 123, 644-657.

Bergman, T.J., Beehner, J.C., Cheney, D.L., Seyfarth, R.M., 2003. Hierarchical classification by rank and kinship in baboons. Science 302, 1234-1236.

Binder, J.R., Desai, R.H., Graves, W.W., Conant, L.L., 2009. Where is the semantic system? A critical review and meta-analysis of 120 functional neuroimaging studies. Cereb Cortex 19, 2767-2796.

Blacher, P., Lecoutey, E., Fresneau, D., Nowbahari, E., 2010. Reproductive hierarchies and status discrimination in orphaned colonies of Pachycondyla apicalis ants. Animal Behaviour 79, 99-105.

Brown, P., Levinson, S.C., 1987. Politeness. Cambridge University Press, Cambridge Cambridgeshire ; New York.

Bunge, S.A., Ochsner, K.N., Desmond, J.E., Glover, G.H., Gabrieli, J.D.E., 2001. Prefrontal regions involved in keeping information in and out of mind. Brain 124, 2074-2086.

Cabeza, R., Ciaramelli, E., Olson, I.R., Moscovitch, M., 2008. The parietal cortex and episodic memory: an attentional account. Nature Reviews Neuroscience 9, 613-625.

Cappa, S.F., 2008. Imaging studies of semantic memory. Current Opinion in Neurology 21, 669-675.

Cavanna, A.E., Trimble, M.R., 2006. The precuneus: a review of its functional anatomy and behavioural correlates. Brain 129, 564-583.

Cheon, B.K., Im, D.M., Harada, T., Kim, J.S., Mathur, V.A., Scimeca, J.M., Parrish, T.B., Park, H.W., Chiao, J.Y., 2011. Cultural influences on neural basis of intergroup empathy. Neuroimage 57, 642-650.

Chiao, J.Y., Harada, T., Oby, E.R., Li, Z., Parrish, T., Bridge, D.J., 2009a. Neural representations of social status hierarchy in human inferior parietal cortex. Neuropsychologia 47, 354-363.

Chiao, J.Y., Mathur, V.A., Harada, T., Lipke, T., 2009b. Neural Basis of Preference for Human Social Hierarchy versus Egalitarianism. In: Atran, S., Navarro, A., Ochsner, K., Tobena, A., Vilarroya, O. (Eds.), Values, Empathy, and Fairness across Social Barriers, pp. 174-181.

de Waal, F.B.M., 1986. The integration of cominance and social bonding in primates Quarterly Review of Biology 61, 459-479.

Freeman, J.B., Rule, N.O., Adams, R.B., Ambady, N., 2009. Culture shapes a mesolimbic response to signals of dominance and subordination that associates with behavior. Neuroimage 47, 353-359.

Friston, K.J., Penny, W.D., Glaser, D.E., 2005. Conjunction revisited. Neuroimage 25, 661-667.

Frith, C.D., Frith, U., 2006. The neural basis of mentalizing. Neuron 50, 531-534.

Fukada, A., Asato, N., 2004. Universal politeness theory: application to the use of Japanese honorifics. Journal of Pragmatics 36, 1991-2002.

Gandiga, P.C., Hummel, F.C., Cohen, L.G., 2006. Transcranial DC stimulation (OCS): A tool for double-blind sham-controlled clinical studies in brain stimulation. Clinical Neurophysiology 117, 845-850.

Gerardin, E., Sirigu, A., Lehericy, S., Poline, J.B., Gaymard, B., Marsault, C., Agid, Y., Le Bihan, D., 2000. Partially overlapping neural networks for real and imagined hand movements. Cerebral Cortex 10, $1093-1104$.

Gilboa, A., Winocur, G., Grady, C.L., Hevenor, S.J., Moscovitch, M., 2004. Remembering our past: Functional neuroanatomy of recollection of recent and very remote personal events. Cerebral Cortex 14, 1214-1225.

Goffman, E., 1959. The presentation of self in everyday life. Doubleday, Garden City, N.Y. 
Greene, J., Haidt, J., 2002. How (and where) does moral judgment work? Trends in Cognitive Sciences 6, 517-523.

Grodzinsky, Y., Friederici, A.D., 2006. Neuroimaging of syntax and syntactic processing. Current Opinion in Neurobiology 16, 240-246.

Grosenick, L., Clement, T.S., Fernald, R.D., 2007. Fish can infer social rank by observation alone (vol 445, pg 429, 2007). Nature 446, 102-102.

Gusnard, D.A., Raichle, M.E., 2001. Searching for a baseline: Functional imaging and the resting human brain. Nature Reviews Neuroscience 2, 685-694.

Hanakawa, T., Immisch, I., Toma, K., Dimyan, M.A., Van Gelderen, P., Hallett, M., 2003. Functional properties of brain areas associated with motor execution and imagery. Journal of Neurophysiology 89, 989-1002.

Hickok, G., Poeppel, D., 2004. Dorsal and ventral streams: a framework for understanding aspects of the functional anatomy of language. Cognition 92, 67-99.

Holmes, E.A., Brown, R.J., Mansell, W., Fearon, R.P., Hunter, E.C.M., Frasquilho, F., Oakley, D.A., 2005. Are there two qualitatively distinct forms of dissociation? A review and some clinical implications. Clinical Psychology Review 25, 1-23.

Homan, R.W., Herman, J., Purdy, P., 1987. Cerebral location of international 10-20 system electrode placement. Electroencephalography and Clinical Neurophysiology 66, 376-382.

Iacoboni, M., Lieberman, M.D., Knowlton, B.J., Molnar-Szakacs, I., Moritz, M., Throop, C.J., Fiske, A.P., 2004. Watching social interactions produces dorsomedial prefrontal and medial parietal BOLD fMRI signal increases compared to a resting baseline. Neuroimage 21, 1167-1173.

Iyer, M.B., Mattu, U., Grafman, J., Lomarev, M., Sato, S., Wassermann, E.M., 2005. Safety and cognitive effect of frontal DC brain polarization in healthy individuals. Neurology 64, 872-875.

Just, M.A., Carpenter, P.A., Keller, T.A., Eddy, W.F., Thulborn, K.R., 1996. Brain activation modulated by sentence comprehension. Science 274, 114-116.

Karafin, M.S., Tranel, D., Adolphs, R., 2004. Dominance attributions following damage to the ventromedial prefrontal cortex. Journal of Cognitive Neuroscience 16, 1796-1804.

Kircher, T.T.J., 2003. Addendum to "The neural correlates of intentional and incidental self-processing” [Neuropsychologia 40 (2002) 683-692]. Neuropsychologia 41, 1279.

Kircher, T.T.J., Senior, C., Phillips, M.L., Benson, P.J., Bullmore, E.T., Brammer, M., Simmons, A., Williams, S.C.R., Bartels, M., David, A.S., 2000. Towards a functional neuroanatomy of self processing: effects of faces and words. Cognitive Brain Research 10, 133-144.

Kjaer, T.W., Nowak, M., Lou, H.C., 2002. Reflective Self-Awareness and Conscious States: PET Evidence for a Common Midline Parietofrontal Core. Neuroimage 17, 1080-1086.

Kokuryu, A., Takechi, H., 2011. Use of honorifics in all situations by a patient with semantic dementia. Nippon Ronen Igakkai Zasshi. Japanese Journal of Geriatrics 48, 558-564.

Lou, H.C., Luber, B., Crupain, M., Keenan, J.P., Nowak, M., Kjaer, T.W., Sackeim, H.A., Lisanby, S.H., 2004. Parietal cortex and representation of the mental Self. Proc Natl Acad Sci U S A 101, 6827-6832.

Lou, H.C., Luber, B., Stanford, A., Lisanby, S.H., 2010. Self-specific processing in the default network: a singlepulse TMS study. Experimental Brain Research 207, 27-38.

Luber, B., Kinnunen, L.H., Rakitin, B.C., Ellsasser, R., Stern, Y., Lisanby, S.H., 2007. Facilitation of performance in a working memory task with rTMS stimulation of the precuneus: Frequency- and time-dependent effects. Brain Research 1128, 120-129.

Mah, L., Arnold, M.C., Grafman, J., 2004. Impairment of social perception associated with lesions of the prefrontal cortex. American Journal of Psychiatry 161, 1247-1255. 
Margulies, D.S., Vincent, J.L., Kelly, C., Lohmann, G., Uddin, L.Q., Biswal, B.B., Villringer, A., Castellanos, F.X., Milham, M.P., Petrides, M., 2009. Precuneus shares intrinsic functional architecture in humans and monkeys. Proceedings of the National Academy of Sciences of the United States of America 106, 20069-20074.

Marsh, A.A., Blair, K.S., Jones, M.M., Soliman, N., Blair, R.J.R., 2009. Dominance and Submission: The Ventrolateral Prefrontal Cortex and Responses to Status Cues. Journal of Cognitive Neuroscience 21, 713-724.

Miranda, P.C., Lomarev, M., Hallett, M., 2006. Modeling the current distribution during transcranial direct current stimulation. Clin Neurophysiol 117, 1623-1629.

Mitchell, J.P., Macrae, C.N., Banaji, M.R., 2006. Dissociable medial prefrontal contributions to judgments of similar and dissimilar others. Neuron 50, 655-663.

Momo, K., Sakai, H., Sakai, K.L., 2008. Syntax in a native language still continues to develop in adults: Honorification judgment in Japanese. Brain and Language 107, 81-89.

Muscatell, K.A., Morelli, S.A., Falk, E.B., Way, B.M., Pfeifer, J.H., Galinsky, A.D., Lieberman, M.D., Dapretto, M., Eisenberger, N.I., 2012. Social status modulates neural activity in the mentalizing network. Neuroimage 60, 17711777.

Nichols, T., Brett, M., Andersson, J., Wager, T., Poline, J.B., 2005. Valid conjunction inference with the minimum statistic. Neuroimage 25, 653-660.

Nitsche, M.A., Liebetanz, D., Lang, N., Antal, A., Tergau, F., Paulus, W., 2003a. Safety criteria for transcranial direct current stimulation (tDCS) in humans. Clinical Neurophysiology 114, 2220-2222.

Nitsche, M.A., Nitsche, M.S., Klein, C.C., Tergau, F., Rothwell, J.C., Paulus, W., 2003b. Level of action of cathodal DC polarisation induced inhibition of the human motor cortex. Clinical Neurophysiology 114, 600-604.

Nitsche, M.A., Paulus, W., 2000. Excitability changes induced in the human motor cortex by weak transcranial direct current stimulation. Journal of Physiology-London 527, 633-639.

Northoff, G., Heinzel, A., Greck, M., Bennpohl, F., Dobrowolny, H., Panksepp, J., 2006. Self-referential processing in our brain - A meta-analysis of imaging studies on the self. Neuroimage 31, 440-457.

Oldfield, R.C., 1971. The assessment and analysis of handedness: the edinburgh inventory. Neuropsychologia 9, 97113.

Oshio, R., Tanaka, S., Sadato, N., Sokabe, M., Hanakawa, T., Honda, M., 2010. Differential effect of double-pulse TMS applied to dorsal premotor cortex and precuneus during internal operation of visuospatial information. Neuroimage 49, 1108-1115.

Paz-y-Mino, G., Bond, A.B., Kamil, A.C., Balda, R.P., 2004. Pinyon jays use transitive inference to predict social dominance. Nature 430, 778-781.

Poreisz, C., Boros, K., Antal, A., Paulus, W., 2007. Safety aspects of transcranial direct current stimulation concerning healthy subjects and patients. Brain Research Bulletin 72, 208-214.

Price, C.J., 2012. A review and synthesis of the first 20years of PET and fMRI studies of heard speech, spoken language and reading. Neuroimage 62, 816-847.

Priori, A., 2003. Brain polarization in humans: a reappraisal of an old tool for prolonged non-invasive modulation of brain excitability. Clinical Neurophysiology 114, 589-595.

Raichle, M.E., Snyder, A.Z., 2007. A default mode of brain function: a brief history of an evolving idea. Neuroimage 37, 1083-1090; discussion 1097-1089.

Ruby, P., Decety, J., 2001. Effect of subjective perspective taking during simulation of action: a PET investigation of agency. Nature Neuroscience 4, 546-550.

Sakai, K.L., 2005. Language acquisition and brain development. Science 310, 815-819.

Sakai, K.L., Noguchi, Y., Takeuchi, T., Watanabe, E., 2002. Selective priming of syntactic processing by eventrelated transcranial magnetic stimulation of Broca's area. Neuron 35, 1177-1182. 
Sakai, K.L., Tatsuno, Y., Suzuki, K., Kimura, H., Ichida, Y., 2005. Sign and speech: amodal commonality in left hemisphere dominance for comprehension of sentences. Brain 128, 1407-1417.

Scheperjans, F., Eickhoff, S.B., Hoemke, L., Mohlberg, H., Hermann, K., Amunts, K., Zilles, K., 2008a. Probabilistic maps, morphometry, and variability of cytoarchitectonic areas in the human superior parietal cortex. Cerebral Cortex 18, 2141-2157.

Scheperjans, F., Hermann, K., Eickhoff, S.B., Amunts, K., Schleicher, A., Zilles, K., 2008b. Observer-independent cytoarchitectonic mapping of the human superior parietal cortex. Cerebral Cortex 18, 846-867.

Shibatani, M., 1990. The languages of Japan. Cambridge University Press, Cambridge ; New York.

Suzuki, K., Sakai, K.L., 2003. An event-related fMRI study of explicit syntactic processing of normal/anomalous sentences in contrast to implicit syntactic processing. Cerebral Cortex 13, 517-526.

Tatsuno, Y., Sakai, K.L., 2005. Language-related activations in the left prefrontal regions are differentially modulated by age, proficiency, and task demands. Journal of Neuroscience 25, 1637-1644.

Tzourio-Mazoyer, N., Landeau, B., Papathanassiou, D., Crivello, F., Etard, O., Delcroix, N., Mazoyer, B., Joliot, M., 2002. Automated anatomical labeling of activations in SPM using a macroscopic anatomical parcellation of the MNI MRI single-subject brain. Neuroimage 15, 273-289.

Vogeley, K., May, M., Ritzl, A., Falkai, P., Zilles, K., Fink, G.R., 2004. Neural correlates of first-person perspective as one constituent of human self-consciousness. Journal of Cognitive Neuroscience 16, 817-827.

Wagner, A.D., Shannon, B.J., Kahn, I., Buckner, R.L., 2005. Parietal lobe contributions to episodic memory retrieval. Trends in Cognitive Sciences 9, 445-453.

Wagner, T., Fregni, F., Fecteau, S., Grodzinsky, A., Zahn, M., Pascual-Leone, A., 2007. Transcranial direct current stimulation: a computer-based human model study. Neuroimage 35, 1113-1124.

Wan, X.H., Nakatani, H., Ueno, K., Asamizuya, T., Cheng, K., Tanaka, K., 2011. The Neural Basis of Intuitive Best Next-Move Generation in Board Game Experts. Science 331, 341-346.

Xu, F.F., Chen, J., 2010. Competition hierarchy and plant defense in a guild of ants on tropical Passiflora. Insectes Sociaux 57, 343-349.

Yoshimura, Y., Macwhinney, B., 2011. Honorifics: A sociocultural verb agreement cue in Japanese sentence processing (vol 31, pg 551, 2010). Applied Psycholinguistics 32, 243-244.

Zhang, S., Li, C.S.R., 2012. Functional connectivity mapping of the human precuneus by resting state fMRI. Neuroimage 59, 3548-3562.

Zink, C.F., Tong, Y.X., Chen, Q., Bassett, D.S., Stein, J.L., Meyer-Lindenberg, A., 2008. Know your place: Neural processing of social hierarchy in humans. Neuron 58, 273-283. 


\section{Figure legends}

Figure. 1. Schema of Experiment 1.

Four kinds of sentence-judgment task were visually presented: Politeness (Po), Semantic (Sem), Syntax (Syn), and Control (Co). The tasks were presented in a block design with two sessions each of 600-s duration. Each task block (15 s) included four trials preceded by an instruction cue ("Politeness”, "Syntax", "Semantic”, or "Square") of $3 \mathrm{~s}$. The stimulus sentence was presented for $3.4 \mathrm{~s}$ and followed by a 0.35-s fixation point. Stimuli were presented and behavioral data were collected using E-prime software (Psychology Software Tools, Inc., Pittsburgh, PA). The mean accuracy rate and the RT for correct responses were computed for Politeness, Syntax, Semantic, Status, and Control tasks.

Figure. 2. Significant fMRI activation in pair-wise comparisons.

(A) The simple contrasts for three tasks against the Control. "Po vs. Co", "Sem vs. Co", and "Syn vs. Co" showed similar activation of the left IFG and SPL. (B) The Politeness condition to the two other language tasks. "Po vs. Sem” and "Po vs. Syn” showed similar activation of the precuneus and bilateral IPL.

Figure. 3. Brain activation associated with politeness.

Conjunction analysis of "Po vs. Sem”, "Po vs Syn” and "Po vs. Co" showed activation of the precuneus.

Figure. 4. Correlation analysisbetween brain activation and performance.

A negative correlation between the accuracy rate and the \% signal change of precuneus in the "Politeness vs. Control” contrast.

Figure. 5. Effects of cathodal tDCS on task performance (Experiment 2).

The mean accuracy rates for the Politeness, Semantic, and Syntax tasks in the real cathodal and sham tDCS conditions. A significant difference between these conditions was found only for the Politeness task. ${ }^{*} \mathrm{p}<0.01$. 


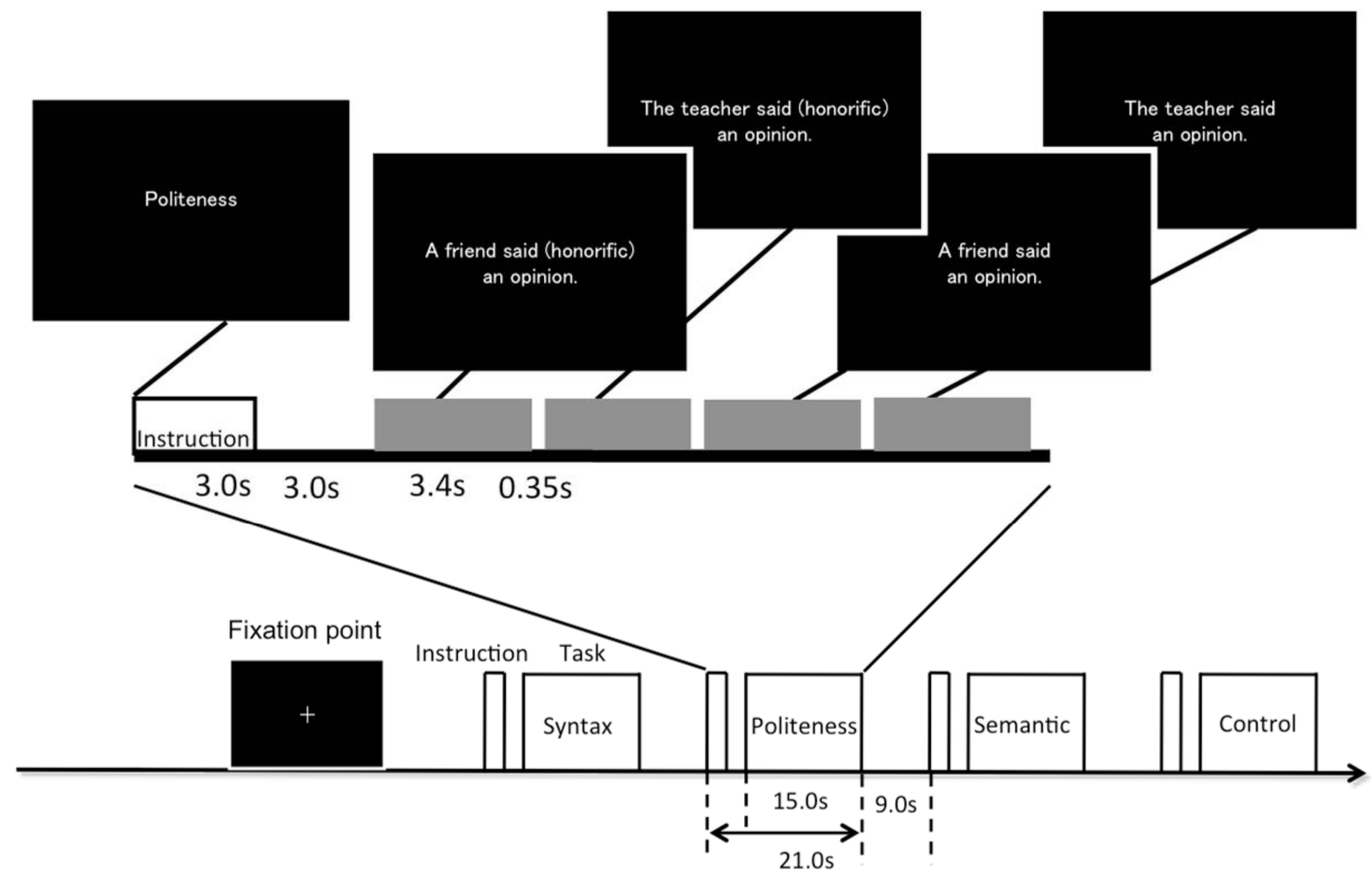

Figure. 1 
A

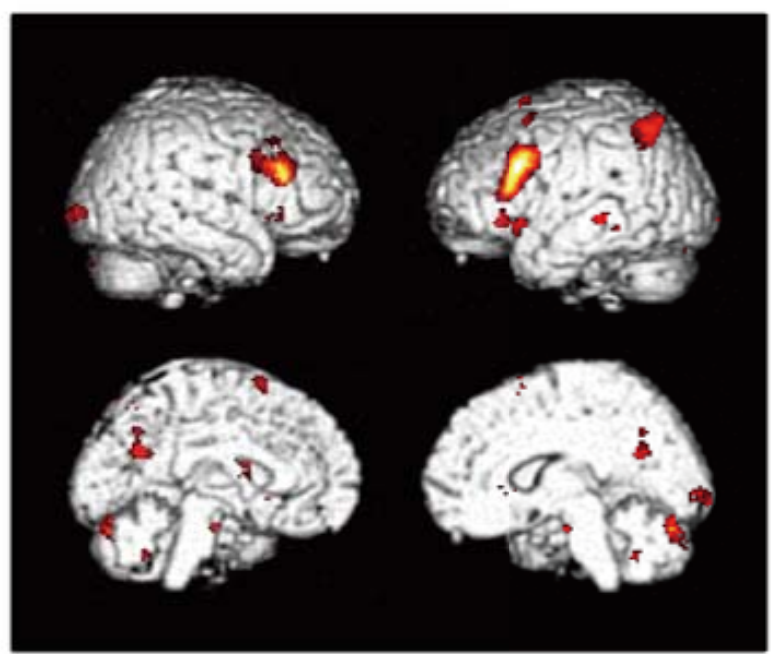

Po vs. Co

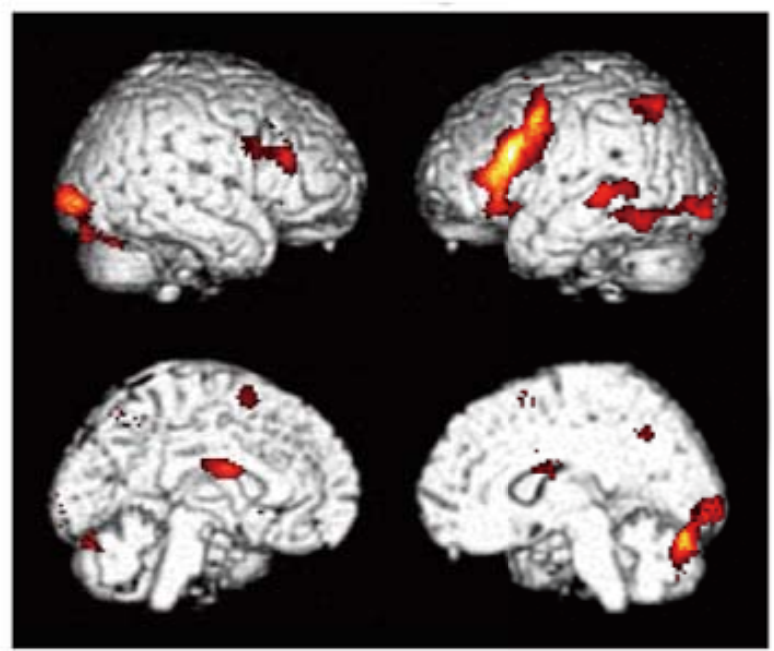

Sem vs. Co

B

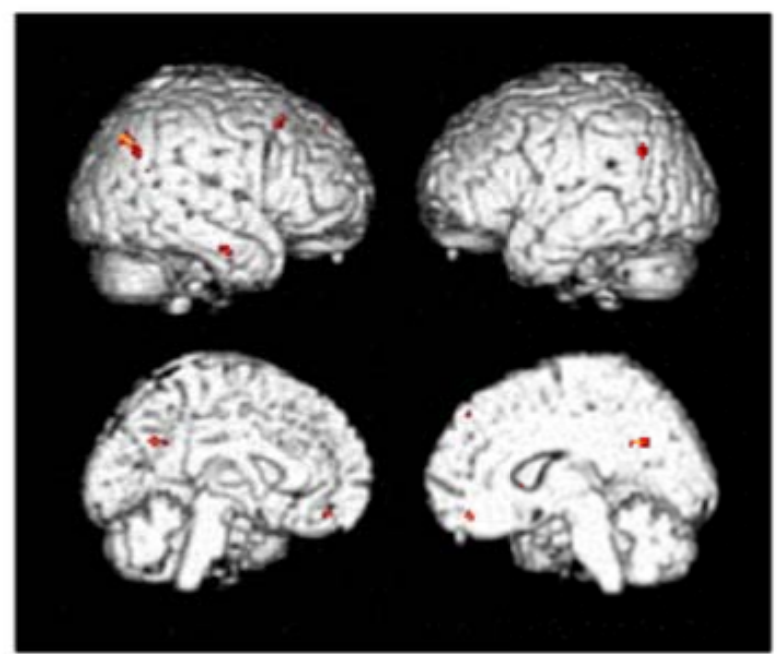

Po vs. Sem

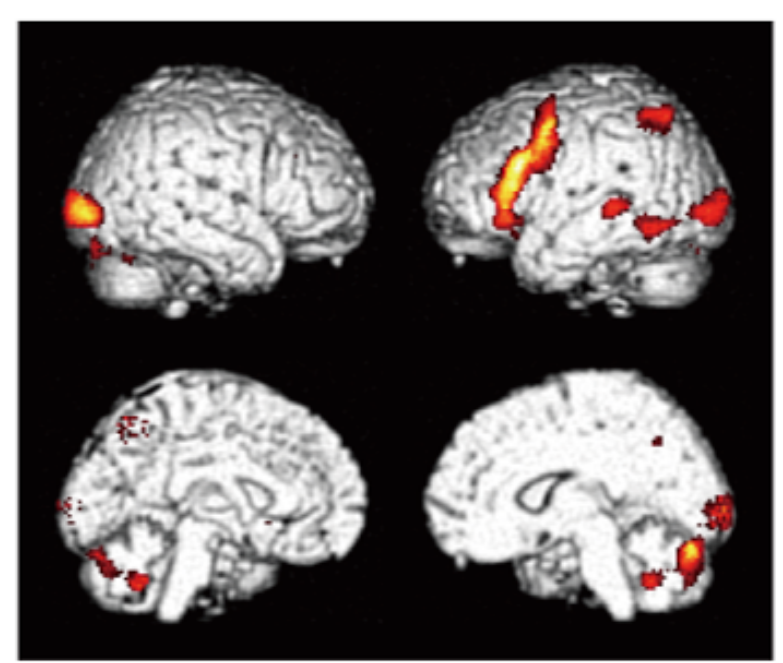

Syn vs. Co

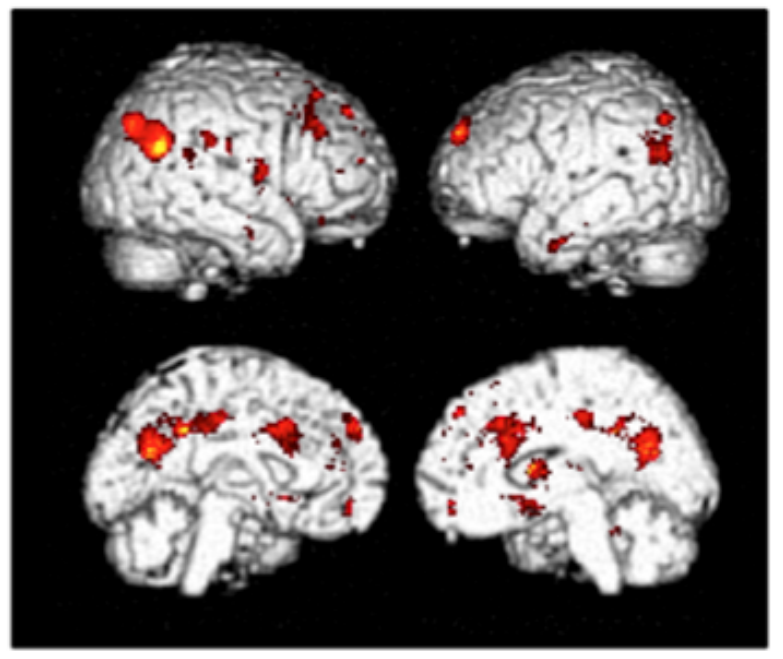

Po vs. Syn 


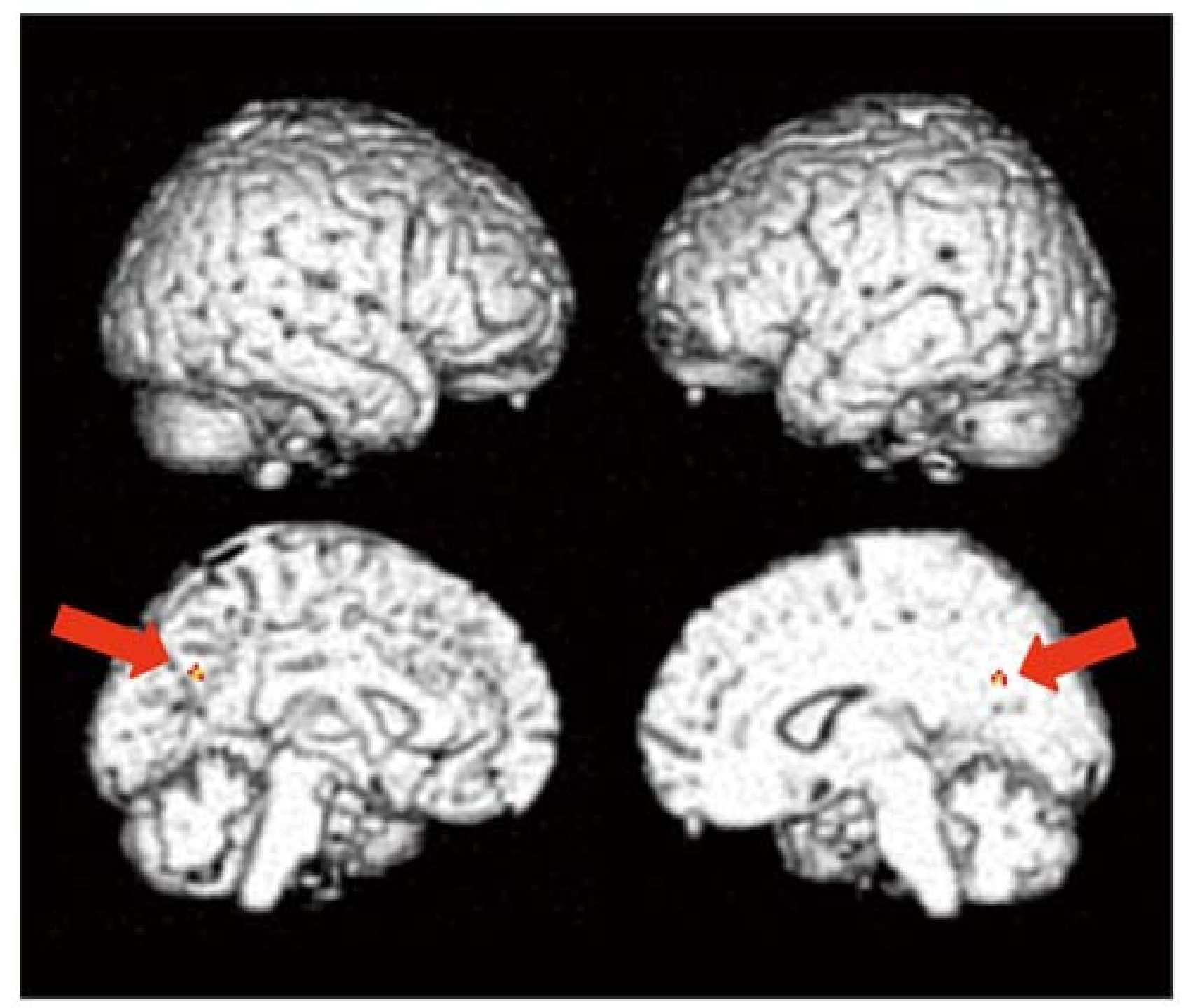

Conjunction analysis

(Po vs. Co, Po vs. Sem, Po vs. Syn)

Figure. 3 
Correctness (Po task)

Precuneus

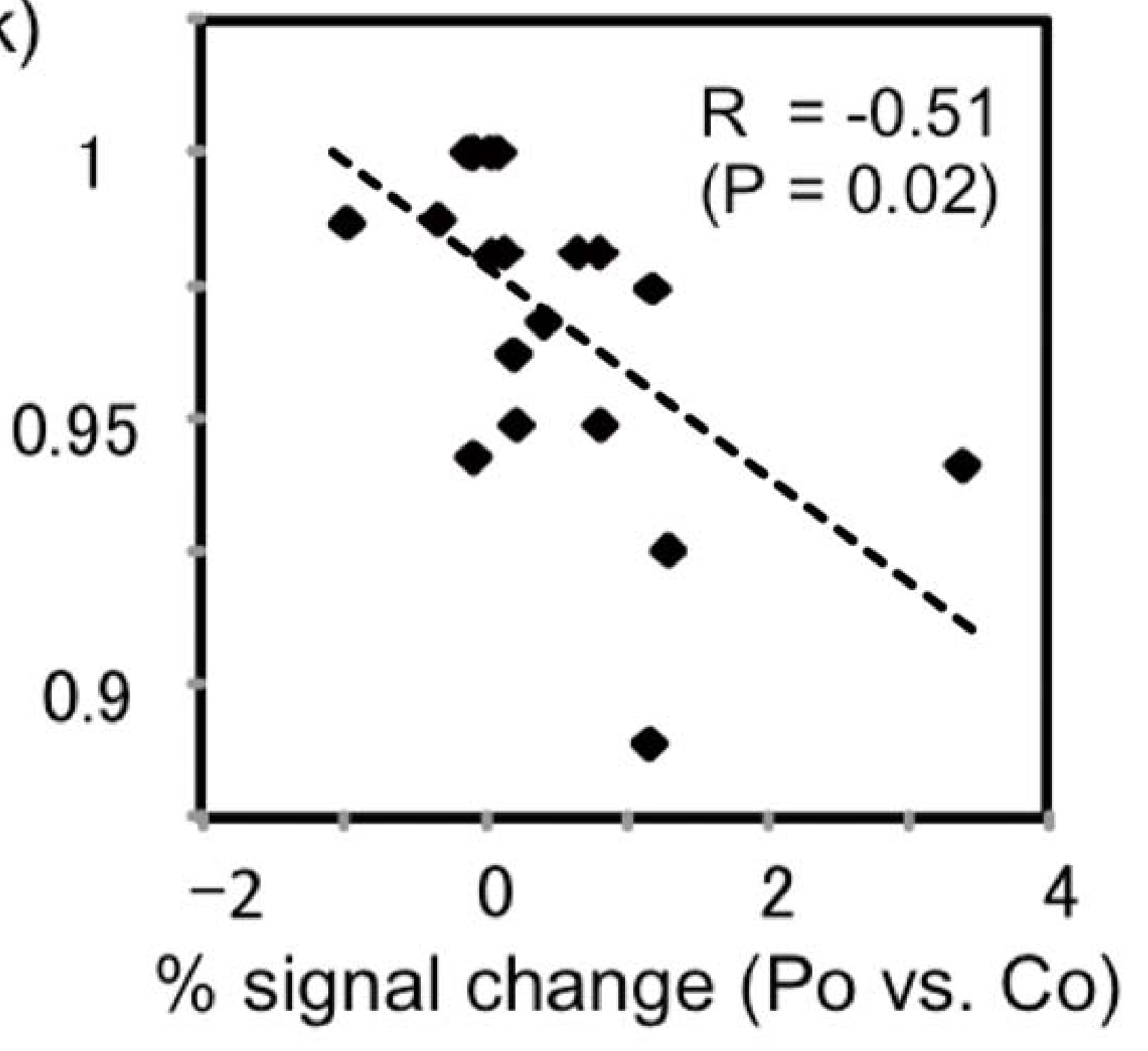

Figure. 4 


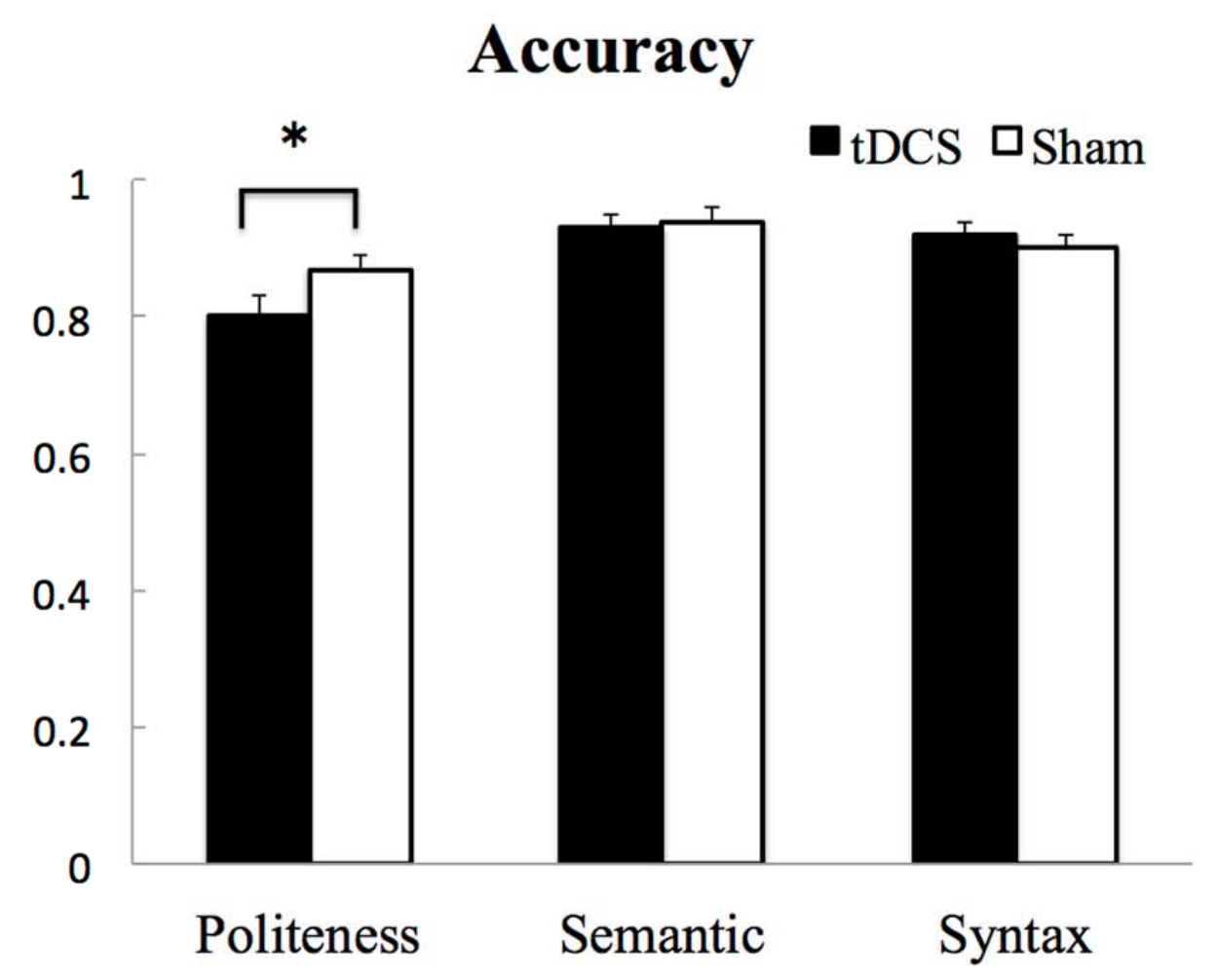

Figure . 5 


\section{Table 1}

Examples of sentence stimuli.

\begin{tabular}{|l|l|}
\hline Correct Sentence & $\begin{array}{l}\text { Sensei-ga iken-o ossyata. } \\
\text { 'The teacher said (honorific) an opinion.' } \\
\text { Tomodachi-ga iken-o itta. } \\
\text { 'A friend said (normal) an opinion.' }\end{array}$ \\
\hline Politeness Error & $\begin{array}{l}\text { Sensei-ga iken-o itta. } \\
\text { 'The teacher said (normal) an opinion.' } \\
\text { Tomodachi-ga iken-o ossyatta. } \\
\text { 'A friend said (honorific) an opinion.' }\end{array}$ \\
\hline Semantic Error & $\begin{array}{l}\text { Sensei-ga iken-o meshiagatta. } \\
\text { 'The teacher ate (honorific) an opinion.' }\end{array}$ \\
\hline Syntax Error & $\begin{array}{l}\text { Sensei-ga iken-de ossyatta. } \\
\text { 'The teacher said (honorific) with an opinion.' }\end{array}$ \\
\hline Control Target & $\begin{array}{l}\text { Sensei-ga } \square \text { iken-o ossyatta. } \\
\text { 'The teacher said an opinion.' } \\
\text { (white square in the middle) }\end{array}$ \\
\hline
\end{tabular}


Table 2

Region of gray matter with Po vs. Co, Sem vs. Co, and Syn vs.Co contrasts.

\begin{tabular}{|c|c|c|c|c|c|c|}
\hline & \multirow[t]{2}{*}{ Regions } & \multicolumn{3}{|c|}{ Cluster centers } & \multirow[t]{2}{*}{ Zvalue } & \multirow[t]{2}{*}{ Chuster size } \\
\hline & & $\mathbf{x}$ & $\mathrm{y}$ & $\mathbf{z}$ & & \\
\hline \multirow[t]{13}{*}{ Po vs. Co } & L. Middle and Inferior Frontal Gyrus (MFG/IFG) & -46 & 19 & 21 & 4.55 & 1052 \\
\hline & L. Superior Parietal Lobe (SPL) & -32 & -60 & 48 & 4.47 & 401 \\
\hline & R.MFG/IFG & 42 & 26 & 21 & 4.37 & 732 \\
\hline & R. Insula & 30 & 24 & 0 & 4.03 & 206 \\
\hline & L. IFG & -26 & 18 & -6 & 3.93 & 195 \\
\hline & L. Superior Frontal Gyrus & -6 & 14 & 66 & 3.85 & 51 \\
\hline & L. Lentiform Nucleus & -20 & 2 & 18 & 3.83 & 58 \\
\hline & R. Cerebelhum & 8 & -80 & -22 & 3.79 & 230 \\
\hline & Precuncus & -2 & 60 & 26 & 3.73 & 124 \\
\hline & L. Middle Temporal Gyrus & -56 & -34 & -4 & 3.73 & 55 \\
\hline & L. MFG & -40 & 12 & 58 & 3.59 & 24 \\
\hline & R. Cerebellum & $\mathbf{0}$ & -58 & -38 & 3.49 & 22 \\
\hline & R. Middle Occipital Gyrus & 26 & -92 & $\mathbf{0}$ & 3.47 & 89 \\
\hline \multirow[t]{11}{*}{ Sem vs. Co } & L. MFG/IFG & -46 & 18 & 26 & 6.05 & 3281 \\
\hline & L. Caudate & -6 & -2 & 20 & 5.54 & 244 \\
\hline & L. SPL & -30 & -64 & 52 & 4.56 & 502 \\
\hline & R. MFG/IFG & 38 & 10 & 28 & 4.52 & 524 \\
\hline & L. Middle Temporal Gyrus & -56 & -34 & $\mathbf{0}$ & 4.49 & 390 \\
\hline & R. Middle Occipital Gyrus & 18 & -82 & -20 & 4.49 & 1311 \\
\hline & R. Fusiform Gyrus & -46 & -58 & -14 & 4.15 & 574 \\
\hline & L. SFG & -4 & 8 & 60 & 3.88 & 72 \\
\hline & R. SPL & 30 & -58 & 40 & 3.69 & 147 \\
\hline & R. Caudate & 8 & $\mathbf{0}$ & 22 & 3.6 & 31 \\
\hline & R. Insula & 32 & 24 & $\mathbf{0}$ & 3.22 & 13 \\
\hline \multirow[t]{12}{*}{ Syn vs. Co } & L. MFG/IFG & -46 & 4 & 38 & 5.8 & 2570 \\
\hline & L. Inferior Temporal Gyrus & -38 & -58 & -8 & 4.98 & 277 \\
\hline & R. Cerebellum & 14 & -78 & -24 & 4.49 & 446 \\
\hline & L. SPL & -30 & -52 & 48 & 433 & 634 \\
\hline & R. Middle Occipital Gyrus & 28 & -92 & $\mathbf{0}$ & 4.16 & 761 \\
\hline & L. Middle Temporal Gyrus & -56 & -34 & 2 & 3.96 & 211 \\
\hline & R. Cerebellum & $\mathbf{0}$ & -58 & -38 & 3.96 & 156 \\
\hline & L. Middle Occipital Gyrus & -32 & -82 & $\mathbf{0}$ & 3.88 & 431 \\
\hline & R. SPL & 28 & -60 & 40 & 3.72 & 72 \\
\hline & L. Cerebelhum & -6 & -80 & -22 & 3.72 & 103 \\
\hline & R. IFG & 40 & 6 & 30 & 3.5 & 16 \\
\hline & R. Cerebellum & 36 & -66 & -26 & 3.3 & 18 \\
\hline
\end{tabular}

Coordinates reported in MNI convention. Results presented at a threshold of cluster-size corrected p $<0.05$ (voxel-based threshold of $\mathrm{p}<\mathbf{0 . 0 0 1 )}$. 
Table 3

Region of gray matter with Po vs. Syn, Po vs. Sem contrasts and Conjunction analysis.

\begin{tabular}{|c|c|c|c|c|c|c|}
\hline & \multirow[t]{2}{*}{ Regions } & \multicolumn{3}{|c|}{ Cluster centers } & \multirow[t]{2}{*}{ Zvalue } & \multirow[t]{2}{*}{ Cluster size } \\
\hline & & $\mathbf{x}$ & $\mathrm{y}$ & $\mathrm{z}$ & & \\
\hline \multirow[t]{6}{*}{ Po vs. Sem } & R. Inferior Temporal Gyrus & 61 & -11 & -21 & 3.49 & 13 \\
\hline & R. MFG & 28 & 22 & 45 & 3.46 & 17 \\
\hline & L. IPL & -57 & -57 & 34 & 3.34 & 11 \\
\hline & R. Anterior Cingulate & 4 & 44 & -16 & 3.3 & 12 \\
\hline & Precumeus & 6 & -53 & 30 & 3.29 & 24 \\
\hline & R. IPL & 46 & -60 & 36 & 3.25 & 56 \\
\hline \multirow[t]{19}{*}{ Povs. Syn } & R. Lentiform Nucleus & 24 & 2 & 10 & 5.25 & 645 \\
\hline & R. IPL & 48 & -74 & 32 & 4.38 & 594 \\
\hline & R. SFG & 32 & 32 & 56 & 4.45 & 482 \\
\hline & Precuneus & 2 & -66 & 22 & 4.24 & 576 \\
\hline & L. Fusiform Gyrus & -54 & -4 & 30 & 4.22 & 32 \\
\hline & L. SFG & -18 & 54 & 34 & 4.01 & 126 \\
\hline & R. Superior Temporal Gyrus & 68 & -42 & 20 & 3.98 & 16 \\
\hline & L. Superior Temporal Gyrus & -58 & -62 & 22 & 3.87 & 130 \\
\hline & R. Anterior Cingulate & 6 & 18 & 28 & 3.86 & 286 \\
\hline & R. Claustrum & 30 & -24 & 12 & 3.81 & 40 \\
\hline & R. Cingulate Gyrus & 4 & -24 & 42 & 3.76 & 88 \\
\hline & R. IPL & 68 & -30 & 28 & 3.57 & 45 \\
\hline & L. MFG & 0 & 52 & -10 & 3.55 & 47 \\
\hline & L. IPL & -46 & -68 & 46 & 3.52 & 50 \\
\hline & L. Anterior Cingulate & 0 & 16 & -4 & 3.49 & 18 \\
\hline & R. Lentiform Nucleus & 24 & 12 & -8 & 3.46 & 30 \\
\hline & P. IPL & 58 & -20 & 24 & 3.36 & 20 \\
\hline & L. MFG & -6 & 42 & 28 & 3.21 & 12 \\
\hline & Precuneus & 6 & -56 & 30 & 3.29 & 24 \\
\hline $\begin{array}{l}\text { Conjunction analysis } \\
\text { (PO vs. Co, PO vs. } \\
\text { Sem, Po vs. Syn) }\end{array}$ & Precuneus & 2 & -60 & 29 & 3.32 & 12 \\
\hline
\end{tabular}

Coordinates reported in MNI convention. Results presented at a threshold of cluster-size corrected $p<0.05$ (voxelbased threshold of $\mathrm{p}<\mathbf{0 . 0 0 1 )}$. 